\title{
Effect of Commercial Effervescent Vitamin Tablets on Bovine Enamel
}

\author{
Moon-Jin Jeong ${ }^{1}$, Myoung-Hwa Lee', Soon-Jeong Jeong ${ }^{2}$, So-Jeong $\mathrm{Kim}^{3}$, \\ Myeong-Ji Ko ${ }^{3}$, Hye-Won Sim³, Ju-Young Lee, Ae-Jung $\mathrm{Im}^{3}$, and Do-Seon $\mathrm{Lim}^{3, \dagger}$ \\ 'Department of Oral Histology and Developmental Biology, College of Dentistry, Chosun University, Gwangju 61452, \\ ${ }^{2}$ Department of Dental Hygiene, College of Health Sciences, Youngsan University, Yangsan 50510, \\ ${ }^{3}$ Department of Dental Hygiene, College of Health Science, Eulji University, Seongnam 13135, Korea
}

\begin{abstract}
Background: In this study, four types of effervescent vitamins marketed in Korea were analyzed for their acidity and vitamin content. For this purpose, bovine teeth were immersed in vitamin, and surface microhardness and appearance were measured before and after immersion to evaluate tooth demineralization and erosion.

Methods: Bovine permanent incisors with sound surface enamel were cut to $5 \times 5 \mathrm{~mm}$ size, embedded in acrylic resin, and polished using a polishing machine with Sic-paper. The prepared samples were analyzed for $\mathrm{pH}$, vitamin content, and surface hardness before and after immersion using a surface microhardness meter. Demineralization of surface dental enamel was observed using a scanning electron microscope.

Results: The average $\mathrm{pH}$ of the four effervescent vitamins was less than 5.5; the $\mathrm{pH}$ of the positive control Oronamin $\mathrm{C}$ was the lowest at 2.76, while that of the negative control Samdasoo was the highest at 6.86. The vitamin content was highest in Berocca and lowest in the DM company Multivitamin. On surface microhardness analysis, surface hardness values of all enamel samples were found to be decreased significantly after 1 and 10 minutes of immersion $(p<0.05)$. After 10 minutes of immersion, there was a significant difference in the decrease in hardness between the experimental groups $(p<0.05)$. Scanning electron microscopy observation showed that dental enamel demineralization after 10 minutes of immersion was the most severe in Oronamin $C$ except for Samdasoo, followed by DM company Multivitamin and VitaHEIM. Immersion in BeroNew and Berocca resulted in similar effects. Conclusion: There is a risk of tooth erosion due to decreased tooth surface microhardness when using the four types of effervescent vitamins and vitamin carbonated beverages with $\mathrm{pH}$ below 5.5. Therefore, high $\mathrm{pH}$ vitamin supplements are recommended to prevent tooth erosion.
\end{abstract}

Key Words: Dental enamel, Effervescent vitamin, Surface microhardness, Tooth demineralization, Tooth erosion

\section{Introduction}

Vitamins are essential for life. Despite the small dosage required for an animal's normal development and nutrition, they must be consumed through other natural sources because these organic compounds cannot be naturally synthesized $^{1)}$. There are various types of vitamins and vitamin groups that are known to differentially affect overall health and dental formation. It has been reported that vitamin A insufficiency is associated with incomplete teeth development, vitamin B complex deficiency reduces tooth decay activity, vitamin $\mathrm{D}$ deficiency can lead to incomplete enamel formation and result in a high number of tooth decays, and vitamin $\mathrm{K}$ inhibits the enzymes necessary for the decomposition of sugar ${ }^{2)}$.

With recent improvement in living standards, the consumer culture is changing in various ways. There have been various changes in the consumption of food with growing interest in health and beauty ${ }^{3)}$. With development in food processing technology along with the changes in 
the consumption patterns, the demand and consumption of various types of favorite foods is increasing due to changes in the diet ${ }^{4)}$.

Energy drinks, which are highly caffeinated beverages currently sold as indulgence food, are popular among adolescents, college students, and office workers ${ }^{4}$. Furthermore, the demand for carbonated drinks such as soda is also increasing due to the perception that they are healthy beverages ${ }^{5)}$. In addition, with increasing interest in healthy food, sale of health function foods has increased rapidly. Single and effervescent vitamin products, specifically, have been driving this rapid growth ${ }^{6}$. The vitamin supplements in the market are classified into natural and synthetic vitamins. Natural vitamins are derived from natural materials such as fruits, vegetables, grains, and fish. In addition to vitamins, they also contain natural by-products such as protein and sugars. Approximately $80 \sim 100 \%$ are absorbed in the body. Synthetic vitamins are made from a molecular structure that is chemically equivalent to natural ingredients, and have an absorption rate of $10 \%^{7)}$. Effervescent vitamin products containing a variety of vitamins and minerals include soluble organic acids and alkaline metal carbonates. These compounds form carbon dioxide on contact with water to produce an effervescent effect; however, they can also act as corrosive agents ${ }^{8)}$.

Meanwhile, major ailments that cause damage to the dental hard tissues include tooth erosion and tooth decay. Recently, there have been many reports of tooth erosion caused by acidic drinks. Tooth decay refers to the mineral loss of dental hard tissues caused by acid produced by bacteria in the mouth ${ }^{9)}$; while tooth erosion refers to the irreversible loss of dental hard tissues due to the chemical reaction of an endogenous or exogenous acid, regardless of bacteria. The internal factor that causes tooth erosion is gastric acid coming into contact with teeth as a result of vomiting and gastrointestinal reflux due to digestive problems $^{10)}$, while the external factor is diet, such as the consumption of acidic carbonated beverages or vitamin supplements, acidic food, and acidic fruits such as citruses $^{11)}$. Over the past few decades, much research has been conducted on the erosive potential of dietary substances. As a result, diverse beverages and food, including soft drinks, sports drinks, alcoholic beverages, juice, salad dressing, herbal tea, and vinegar, were found to contribute to erosion ${ }^{12)}$. Some studies have reported the erosive potential of effervescent tablets and effervescent medications or vitamin $\mathrm{C}$ supplements in particular ${ }^{12,13)}$.

In their research on acidic beverages and tooth erosion, Attin et al. ${ }^{14)}$ examined enamel loss caused by Coca-Cola and orange juice; Choi et al. ${ }^{15)}$ reported that frequently consuming highly acidic beverages leads to enamel loss. Furthermore, Sim et al. ${ }^{16)}$ reported that tooth erosion occurs in lactic-acid fermented milk; Brunton and Hussain ${ }^{17}$ reported that tooth erosion occurs in black tea and herbal tea; and Birkhed ${ }^{18)}$ reported that tooth erosion occurs in sports drinks. Hooper et al. ${ }^{19)}$ stated that enamel demineralization differs with the $\mathrm{pH}$ of the beverage and the type of acid in the beverage, while Sánchez et al. ${ }^{20)}$ reported that tooth erosion increases with the consumption of low-pH beverages. In their study on tooth erosion caused by vitamins, Wegehaupt et al. ${ }^{21)}$ reported that effervescent tablets including vitamins and vitamin complexes cause erosion. In addition, Choi et al. $^{22)}$ reported that some vitamin supplements sold in the market affect the surface and hardness of primary molars. Bahal and Djemal ${ }^{1)}$ reported that overconsumption of vitamin $\mathrm{C}$ leads to erosion. Research on enamel erosion due to low-acidic beverages has been conducted ${ }^{23)}$, but the research on effervescent vitamins produced so that people who cannot easily take pills can take it in the form of a carbonated beverages, is lacking.

Therefore, this study aims to identify the effects of some effervescent vitamins currently sold in Korea on dental enamel erosion, by observing the demineralization using a scanning electron microscope (SEM) and measuring the changes in the tooth surface using the Micro Vickers Hardness Tester, in order to contribute to a desirable selection of effervescent vitamins for oral health in the future.

\section{Materials and Methods}

\section{Research materials}

Bovine permanent incisors with a sound surface enamel were selected. They were stored in normal saline and used 
in this experiment. Four types of effervescent vitamins currently sold in the market were selected. To compare the changes in the enamel surface by $\mathrm{pH}$ differences, Oronamin C (vitamin carbonated beverage) was selected as the positive control and Samdasoo as the negative control (Table 1).

\section{Research methods}

\section{1) $\mathrm{pH}$ measurement}

To measure the $\mathrm{pH}$ at identical temperatures, the control group and the experimental group samples were stored at room temperature $\left(25^{\circ} \mathrm{C}\right)$ for six hours. Then, one tablet each of the effervescent vitamins was completely dissolved in $200 \mathrm{ml}$ of water. The $\mathrm{pH}$ of each beverage was measured three times using the $\mathrm{pH}$ meter ( $\mathrm{S} 2 \mathrm{OK} \mathrm{pH}$ meter; Mettler-Toledo, Leicester, UK), and the mean value was calculated.

\section{2) Investigation of the vitamin content}

Using the nutrition label of each product in the control group and the experimental group, the total vitamin content of each group was investigated.

\section{3) Sample production}

The selected bovine permanent incisors were scaled and cleaned on the surface and stored in saline solution. Then, each tooth was cut to $5 \times 5 \mathrm{~mm}$ using a cutting disc (Saejong Ind., Siheung, Korea). Afterward, these were placed in rubber molds so that the enamel surface was exposed, and acrylic resin (Lang Dental Manufacturing

Table 1. Beverages Used in the Experiment

\begin{tabular}{|c|c|c|}
\hline Classification & Brand name & Manufacturer \\
\hline $\begin{array}{l}\text { Negative } \\
\text { control group }\end{array}$ & Samdasoo & $\begin{array}{l}\text { Jeju province development } \\
\text { Co., Jeju, Korea }\end{array}$ \\
\hline $\begin{array}{l}\text { Positive } \\
\text { control group }\end{array}$ & Oronamin C & $\begin{array}{l}\text { Donga-otsuka Co., Seoul, } \\
\text { Korea }\end{array}$ \\
\hline \multirow[t]{4}{*}{$\begin{array}{l}\text { Experimental } \\
\text { group }\end{array}$} & $\begin{array}{l}\text { DM Co. } \\
\text { Multivitamin }\end{array}$ & DM Co., Karlsruhe, Germany \\
\hline & BeroNew & Bayer Korea Co., Seoul, Korea \\
\hline & Berocca & Bayer Korea Co., Seoul, Korea \\
\hline & VitaHEIM & $\begin{array}{l}\text { Nutrilo GmbH, Cuxhaven, } \\
\text { Germany }\end{array}$ \\
\hline
\end{tabular}

Co., Inc., Wheeling, IL, USA) was poured to embed them. To make the surface smooth, polishing was done with the polishing machine (Struers LaboPol-5, Type 05206133; Struers, Ballerup, Denmark) using Sic-paper \#1200 and \#4000. Four samples in the negative control group and nine samples for each length of immersion in each beverage in the experimental and positive control groups were selected, leading to a total of 94 samples.

\section{4) Measurement of the surface hardness of each sample}

To measure the changes in the surface hardness of the polished samples, Micro Vickers Hardness Tester (MMT-X7B; Matsuzawa, Akita, Japan) was used to measure the Vickers hardness number (VHN) before immersion into the beverages. To do so, the four surfaces (top, bottom, left, and right) of the sample were placed perpendicular to the direction of the pressure and pressured for 10 seconds with a weight of $200 \mathrm{~g}$ before measuring the VHN at a magnification of $\times 400$. After immersion, the samples were sufficiently cleaned with distilled water and the surface hardness was measured using a method identical to that described above for measurement before immersion. The samples used in the experiment were those in which the normal VHN of the enamel was within the range of $300 \pm 30$.

\section{5) Immersion}

After simultaneously dissolving each of the four types of effervescent vitamins in $200 \mathrm{ml}$ of water and $100 \mathrm{ml}$ of Samdasoo, four solutions of effervescent vitamins and Oronamin $\mathrm{C}$ were each poured in identical beakers. Then, the samples in the control and experimental groups were immersed for one minute and 10 minutes.

\section{6) Scanning electron microscope}

To examine the demineralization of the enamel surface after one minute and 10 minutes of immersion in the control and experimental groups, each sample was dried using a Critical point dryer (HCP-2; Hitachi, Tokyo, Japan). Each dried sample was fixed to the stub with double-sided tape and sheathed in platinum in the Ion sputter (E-1030; Hitachi). Then, each sample was 
observed under the SEM (S-4700; Hitachi), with $10 \mathrm{kV}$ current and magnification of $\times 500$ and $\times 5,000$. The standards of analysis were the following three items to observe the enamel surface of each sample: roughness (mineral loss), surface cracks, and fistula exposure. Responses: - was recorded if they were not observed, + if very few or $1 \sim 5$ were observed, ++ if periodically and sometimes observed, and +++ if observed in the overall surface (Table 2).

\section{7) Statistical analyses}

To compare the enamel surfaces of the samples of bovine teeth before and after immersion in the experimental beverages, a paired t-test was performed. To compare the changes in the surface hardness value before and after the immersion between groups, a one-way ANOVA was used. Tukey test was performed for post-hoc analysis. For statistical analyses, SPSS ver. 24.0 (IBM Corp., Armonk, NY, USA) was used. Statistical significance was inferred when the p-value was 0.05 or below.

\section{Results}

\section{1. $\mathrm{pH}$ of the beverages}

The $\mathrm{pH}$ of Samdasoo (negative control) was 6.86, while the $\mathrm{pH}$ of the four experimental beverages and the positive

Table 2. Evaluation Standard for SEM Findings

\begin{tabular}{clc}
\hline \multirow{2}{*}{ Marking method } & \multicolumn{1}{c}{ Valuation basis } & Grade (point) \\
\hline- & Not observed & 0 \\
+ & Very little or 1 $\sim 5$ observed & 1 \\
++ & Intermittently observed & 2 \\
+++ & Entirely observed on surface & 3 \\
\hline
\end{tabular}

SEM: scanning electron microscope.

Table 3. The $\mathrm{pH}$ of Beverages

\begin{tabular}{lc}
\hline \multicolumn{1}{c}{ Brand name } & $\mathrm{pH}$ \\
\hline Samdasoo & 6.86 \\
Oronamin C & 2.76 \\
DM Co. Multivitamin & 4.03 \\
BeroNew & 4.66 \\
Berocca & 4.49 \\
VitaHEIM & 4.33 \\
\hline
\end{tabular}

control was 5.5 or below. The mean $\mathrm{pH}$ was the lowest for vitamin carbonated beverage Oronamin C (positive control) at 2.76. Among the effervescent vitamin solutions (experimental group), $\mathrm{pH}$ of DM Multivitamin was the lowest at 4.03 and $\mathrm{pH}$ of BeroNew was the highest at 4.66 (Table 3).

\section{Vitamin content}

The results from comparing the total vitamin contents of the experimental group and the positive control group by the nutrition labels of each product showed that Berocca had the highest vitamin content per $100 \mathrm{ml}$ and DM Multivitamin had the lowest content (Table 4).

\section{Scanning electron microscope observation}

Demineralization of the enamel surfaces of the control and experimental groups after 1 and 10 minutes of immersion was observed using SEM. For samples that were immersed for one minute, the negative control group (Samdasoo) did not show any change and the experimental group showed almost no change. However, a slightly rough surface was observed in the DM Multivitamin sample (Fig. 1). For samples that were immersed for 10 minutes, all samples except Samdasoo showed demineralization. Most demineralization was found in Oronamin C (positive control), followed by DM Multivitamin and VitaHEIM. BeroNew and Berocca were observed to have similar effects (Fig. 2). Meanwhile, enamel surface evaluation by analysis standards also showed roughness, surface cracks, and fistula exposure in all groups except Samdasoo (negative control) when the samples were immersed for 10 minutes. This was most severe for Oronamin C (positive control), followed by DM Multivitamin, VitaHEIM, BeroNew, and Berocca (Table 5).

Table 4. The Concentration Levels of Vitamin

\begin{tabular}{lc}
\hline \multicolumn{1}{c}{ Brand name } & Concentration level $(\mathrm{mg} / 100 \mathrm{ml})$ \\
\hline Oronamin C & 199.42 \\
DM Co. Multivitamin & 59.08 \\
BeroNew & 305.63 \\
Berocca & 312.30 \\
VitaHEIM & 250.00 \\
\hline
\end{tabular}



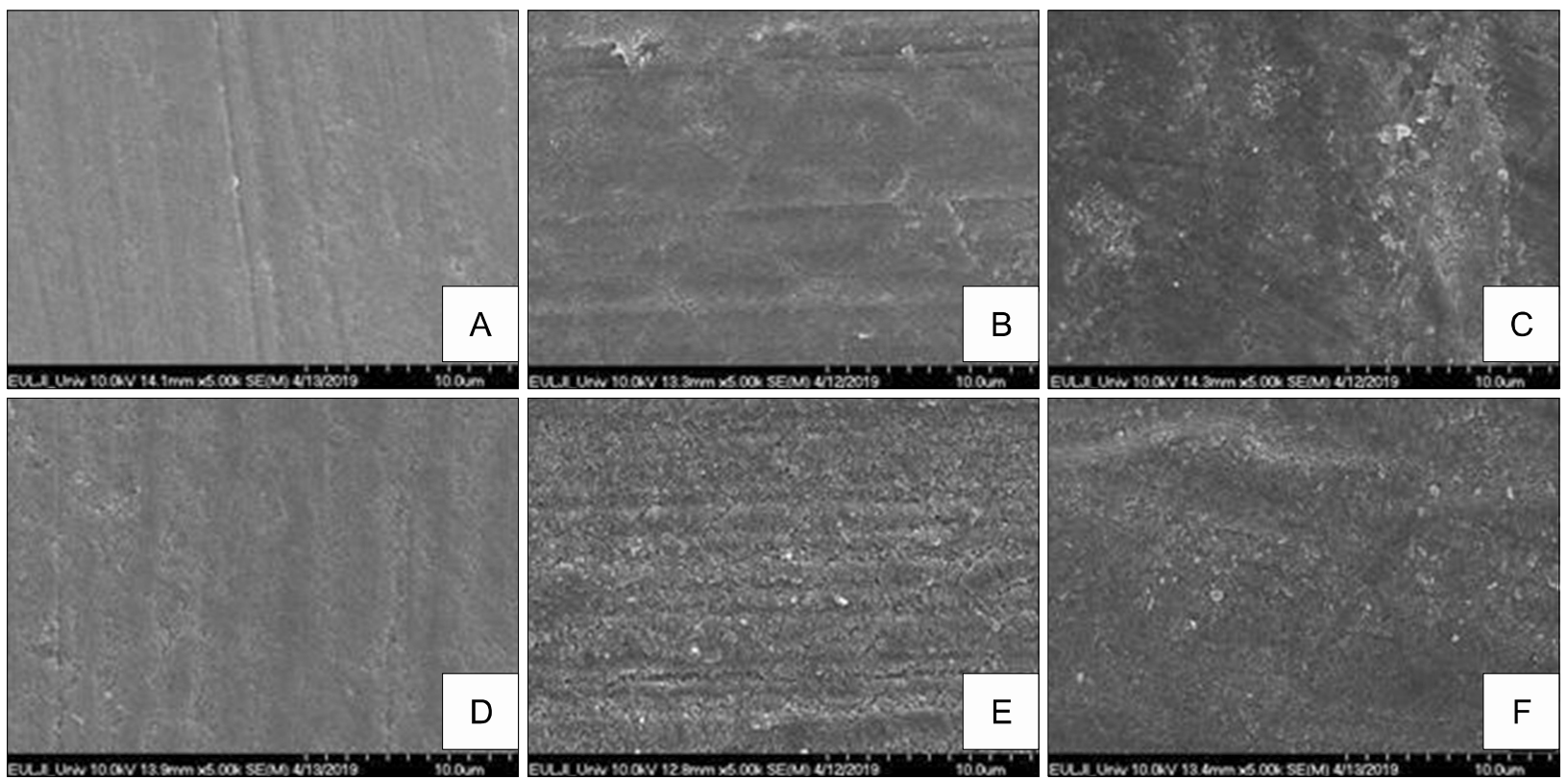

Fig. 1. Scanning electron microscope image of enamel surface after immersion for one minute. Samdasoo, the negative control group, did not change and the experimental group showed little change. However, some rough surface was observed in DM company Multivitamin (A: Samdasoo, B: Oronamin C, C: BeroNew, D: Berocca, E: DM Co. Multivitamin, F: VitaHEIM, All magnification is 5,000 times).

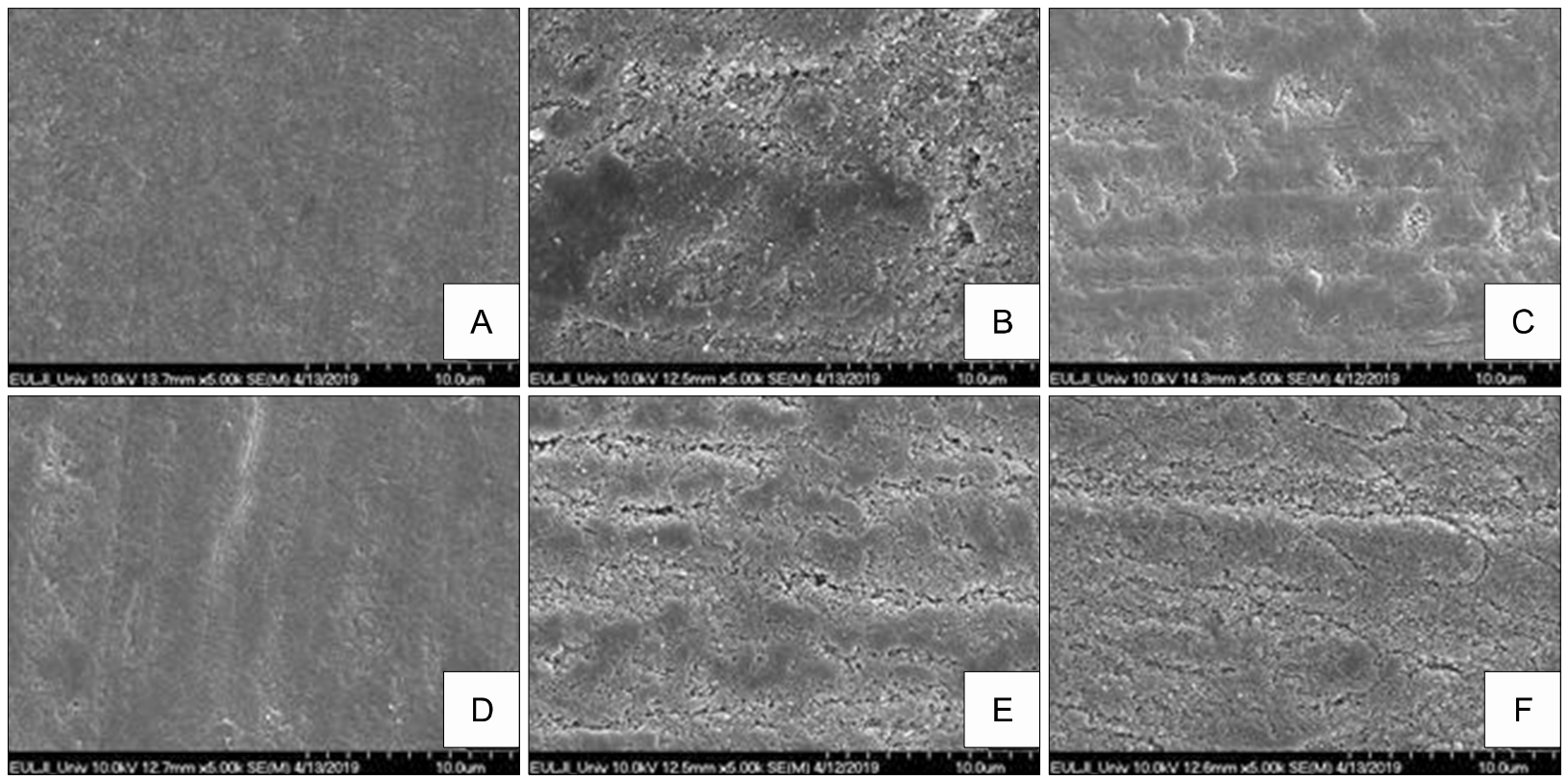

Fig. 2. Scanning electron microscope image of enamel surface after immersion for 10 minutes. This demineralization pattern was observed in all samples except the Samdasoo. In particular, the positive control group showed the most demineralization in Oronamin $\mathrm{C}$, followed by DM company Multivitamin and VitaHEIM, and BeroNew and Berocca were similar pattern (A: Samdasoo, B: Oronamin C, C: BeroNew, D: Berocca, E: DM Co. Multivitamin, F: VitaHEIM, All magnification is 5,000 times).

\section{Changes in the enamel surface hardness}

The surface hardness of the bovine dental enamel sample was measured to compare the differences before and after the immersion into the experimental beverages between groups. The results showed that the surface hardness value decreased in the positive control group (Oronamin C) and all experimental groups after one minute of immersion, but not in the negative control group 
(Samdasoo). These results showed statistically significant differences $(p<0.05)$. The differences in the mean changes in the surface hardness after one minute of immersion among the groups were not statistically significant (Table 6). Likewise, the surface hardness of the enamel decreased after 10 minutes of immersion for the positive control group and all experimental groups, but not for the negative control group. These results showed statistically significant differences $(p<0.05)$. After 10 minutes of immersion, the mean change in the surface

Table 5. Analysis of Enamel Demineralization and SEM Findings after Immersion for 10 Minutes

\begin{tabular}{lccc}
\hline \multicolumn{1}{c}{ Beverage } & Roughness & Crack & Exposure of hole \\
\hline Samdasoo & - & - & - \\
Oronamin C & +++ & +++ & +++ \\
BeroNew & + & + & + \\
Berocca & + & + & - \\
DM Co. Multivitamin & ++ & +++ & ++ \\
VitaHEIM & ++ & ++ & + \\
\hline
\end{tabular}

SEM: scanning electron microscope. hardness of each group revealed that the most drastic reduction was seen in Oronamin $\mathrm{C}$, followed by $\mathrm{DM}$ Multivitamin, VitaHEIM, Berocca, and BeroNew. These results showed statistically significant differences $(\mathrm{p}<$ 0.05 , Table 7).

\section{Discussion}

Beverages collectively represent all the fluids that humans can consume in their daily lives, and they are a major food group used to fulfill the physiological and psychological needs. There are many kinds of beverages, but the first in the market were carbonated drinks. Since the 1970s to the present day, cola and lemon-lime soda have become indispensable in the beverage market ${ }^{24)}$. There have been many advancements in these beverages. Fruit beverages, rice beverages, and plum beverages have continued to become popular, along with beverages with functional ingredients such as sports drinks and hangovercuring beverages. Recently, there have been many changes

Table 6. Differences in Surface Microhardness after Treatment for 1 Minute

\begin{tabular}{lcccrrr}
\hline \multirow{2}{*}{ Beverage } & $\mathrm{n}$ & \multicolumn{2}{c}{ Treatment } & \multicolumn{2}{c}{$\begin{array}{c}\text { Average of } \\
\text { p-value }\end{array}$} & \multicolumn{2}{c}{$\begin{array}{c}\text { p-value } \\
\text { hardness variation }\end{array}$} \\
\cline { 3 - 4 } Samdasoo & 2 & $322.09 \pm 10.47$ & $324.55 \pm 4.56$ & 0.544 & -2.47 \\
Oronamin C & 9 & $316.76 \pm 25.29$ & $283.94 \pm 17.39$ & 0.002 & 32.82 \\
BeroNew & 9 & $325.24 \pm 11.41$ & $284.97 \pm 11.41$ & $<0.001$ & 40.27 \\
Berocca & 9 & $318.62 \pm 15.04$ & $285.86 \pm 19.89$ & $<0.001$ & 32.76 \\
DM Co. Multivitamin & 9 & $323.50 \pm 13.55$ & $293.61 \pm 15.47$ & $<0.001$ & 29.89 \\
VitaHEIM & 9 & $325.11 \pm 22.52$ & $291.99 \pm 18.46$ & $<0.001$ & 33.13 \\
\hline
\end{tabular}

Values are presented as mean \pm standard deviation or number only.

p-value was determined from paired t-test or ANOVA.

Table 7. Differences in Surface Microhardness after Treatment for 10 Minutes

\begin{tabular}{|c|c|c|c|c|c|c|}
\hline \multirow{2}{*}{ Beverage } & \multirow{2}{*}{$\mathrm{N}$} & \multicolumn{2}{|c|}{ Treatment } & \multirow{2}{*}{ p-value } & \multirow{2}{*}{$\begin{array}{c}\text { Average of } \\
\text { hardness variation }\end{array}$} & \multirow{2}{*}{ p-value } \\
\hline & & Before & After & & & \\
\hline Samdasoo & 2 & $318.78 \pm 4.01$ & $323.17 \pm 24.17$ & 0.743 & $9.055^{\mathrm{a}}$ & $<0.05$ \\
\hline Oronamin C & 9 & $318.38 \pm 20.86$ & $245.29 \pm 23.02$ & $<0.001$ & $73.09^{\mathrm{a}}$ & \\
\hline BeroNew & 9 & $318.06 \pm 15.54$ & $287.66 \pm 20.28$ & 0.009 & $30.30^{\mathrm{a}}$ & \\
\hline Berocca & 9 & $334.86 \pm 15.489$ & $293.40 \pm 29.40$ & $<0.001$ & $41.57^{\mathrm{a}}$ & \\
\hline DM Co. Multivitamin & 9 & $323.43 \pm 24.36$ & $263.57 \pm 21.48$ & $<0.001$ & $59.86^{\mathrm{a}}$ & \\
\hline VitaHEIM & 9 & $316.17 \pm 32.20$ & $259.35 \pm 37.42$ & $<0.001$ & $56.83^{\mathrm{a}}$ & \\
\hline
\end{tabular}

Values are presented as mean \pm standard deviation or number only.

p-value was determined from paired t-test or ANOVA.

${ }^{\mathrm{a}}$ The same letter indicates no significant difference by Tukey test at $\alpha=0.05$. 
in the diet due to the "well-being" trend, and various new beverages are being developed in the beverage market ${ }^{23)}$. However, it is already well known that most beverages sold in the market today are acidic. A Korean study measured the acidity of 158 food and beverage items and reported that most beverages other than milk products had a $\mathrm{pH}$ of 4.0 or below ${ }^{25)}$. Furthermore, the consumption of carbonated food, acidic food, acidic fruits such as the citruses $^{11)}$, and medications such as Irontonics or Vitamin $\mathrm{C}$ were reported as causal factors according to the research on tooth erosion due to dietary factors ${ }^{26}$.

If $\mathrm{pH}$ of 5.5 or below persists, there is a loss of calcium in the dental enamel and tooth decay occurs. As the duration of contact of the beverage with teeth is short when the beverage is consumed, a one-time consumption does not have a large impact even if the $\mathrm{pH}$ is low because the saliva acts as a buffer and neutralizes the acidity. However, if the beverages are often consumed or if the vitamin supplements are consumed by holding them orally for a long time, the duration of contact of the acidic food item with the teeth is longer. Then, the $\mathrm{pH}$ in the mouth decreases and there is a risk of calcium loss in the teeth ${ }^{27)}$. In addition, vitamins have a low $\mathrm{pH}$ and high levels of citric acid. Citric acid has an affinity to the tooth enamel; furthermore, there are three carboxyl groups in each molecule, indicating a high content of hydrogen ions. It also has an immediate reaction when it comes in contact with dental enamel. Therefore, enamel erosion in a child who drinks a beverage that includes citric acid every day is said to be proportional to the duration of drinking the said beverage $^{28)}$. Rytömaa et al. ${ }^{29)}$ stated that the $\mathrm{pH}$ level in which the enamel dissolves is 5.5, and acidic food with a $\mathrm{pH}$ level below 4 has a high risk of causing erosion; Lussi and Schaffner ${ }^{30)}$ reported that the consumption of acidic food causes dental erosion; O'Sullivan and Curzon ${ }^{31)}$ stated that the consumption of acidic beverages is increasing the risk of dental erosion in many children. Therefore, this study was conducted to examine the effect of effervescent vitamins, which are consumed in the form of carbonated beverages unlike regular vitamins, on enamel corrosion. The materials used in this study were DM Multivitamin, BeroNew, Berocca, and VitaHEIM which are popular among the effervescent vitamins sold in the market. Samdasoo was selected as the negative control, and Oronamin $\mathrm{C}$ was selected as the positive control. The results of measuring the $\mathrm{pH}$ in this study showed that the $\mathrm{pH}$ of Samdasoo (negative control) was 6.86 and the $\mathrm{pH}$ of the four experimental groups and the positive control was $\mathrm{pH} 5.5$ or below. In other words, vitamin carbonated beverage Oronamin $\mathrm{C}$ (positive control) had the lowest $\mathrm{pH}$ of 2.76; among the effervescent vitamin solutions (experimental group), DM Multivitamin had the lowest $\mathrm{pH}$ of 4.03 and BeroNew had the highest $\mathrm{pH}$ of 4.66. Through the research by Rytömaa et al. ${ }^{29)}$ which found that the $\mathrm{pH}$ threshold under which enamel dissolves is 5.5, and the research by Wegehaupt et al. ${ }^{21)}$ which found that the $\mathrm{pH}$ of all solutions of effervescent vitamins and mineral tablets is within the range of 3.82 to 4.30 , it is predicted that tooth erosion is possible in all groups except Samdasoo.

The samples used in this study were bovine teeth, based on the research by Lee et al. ${ }^{32)}$ which found that permanent teeth and bovine teeth have a similar speed of demineralization. Based on the research by Lee et al. ${ }^{33)}$ who reproduced the general intra-oral conditions by inducing corrosion of teeth by immersing them in an acidic beverage for 10 minutes, the durations of immersion were set to one minute and 10 minutes.

Demineralization of the enamel surface after one minute and 10 minutes of immersion in the control and experimental groups was observed using SEM. For samples that were immersed for one minute, the negative control group (Samdasoo) did not show any change and the experimental group showed almost no change. However, slightly rough surface was observed in the DM Multivitamin sample. For samples that were immersed for 10 minutes, all samples except Samdasoo showed demineralization. In particular, most demineralization was found in Oronamin C (positive control), followed by DM Multivitamin and VitaHEIM. BeroNew and Berocca showed similar results. Meanwhile, enamel surface evaluation by analysis standards also showed roughness, surface cracks, and fistula exposure in all groups except Samdasoo (negative control) when the samples were immersed for 10 minutes. In particular, this was the most severe for Oronamin $\mathrm{C}$ (positive control), followed by DM Multivitamin, VitaHEIM, 
BeroNew, and Berocca. These results support the previous findings that stated that acidic drinks dissolve the outermost layer of enamel, which offers the strongest resistance to tooth decay, and that the surface becomes rougher due to corrosion ${ }^{34,35)}$. These results also support the findings from previous researches which exposed teeth to cola for five minutes and found that demineralization occurred in the dental enamel, and the VHN decreased by $31 \%^{36)}$. Furthermore, these results are similar to the findings by Kim et al. ${ }^{23)}$ who found that the enamel surface in the control group did not undergo much change while it was rougher and damaged in the experimental group on observation under the SEM.

Meanwhile, Maupomé et al. ${ }^{37)}$ reported that the dental hardness decreases with duration and frequency of contact with the acidic beverage. Kim et al. ${ }^{23)}$ also reported that the enamel surface hardness further decreases with the duration of immersion. In this study, the surface hardness was measured to compare the changes in the enamel before and after the immersion in the beverage. As a result, longer duration of immersion was associated with a decrease in the enamel surface hardness. The results showed that the surface hardness value decreased in the positive control group (Oronamin C) and all experimental groups after one minute of immersion, but not in the negative control group (Samdasoo). The mean changes in the surface hardness among the groups were not significantly different. The hardness of enamel decreased after 10 minutes of immersion in the positive control group and all experimental groups, but not in the negative control group. The mean changes in the surface hardness among the groups were significantly different. Therefore, when taking effervescent vitamins, it may be recommended that the beverage be consumed in a short duration (10 minutes or less if possible) and not for a long time or during exercise.

Combining the above results, when taking vitamins to prevent dental corrosion and for supplemental intake, a vitamin supplement with a high $\mathrm{pH}$ level is recommended. Furthermore, various forms of oral health education and information should be provided for the correct perception on vitamins that can affect tooth erosion and maintenance of healthy teeth. This study used simple immersion to simulate oral conditions without considering many environmental aspects of the mouth. Thus, there may be differences from an actual oral environment. Therefore, a study that considers the function of saliva in the mouth and a study on dental corrosion by the type and ingredient in the vitamin will be necessary in the future.

\section{Notes}

\section{Conflict of interest}

No potential conflict of interest relevant to this article was reported.

\section{Ethical approval}

This article does not require an IRB because it used tissue that was thrown away from the carcasses of animals.

\section{ORCID}

Moon-Jin Jeong, https://orcid.org/0000-0002-5547-898X

Myoung-Hwa Lee, https://orcid.org/0000-0003-2291-5589

Soon-Jeong Jeong, https://orcid.org/0000-0002-8959-4663

So-Jeong Kim, https://orcid.org/0000-0003-0157-0112

Myeong-Ji Ko, https://orcid.org/0000-0003-1846-0884

Hye-Won Sim, https://orcid.org/0000-0002-6159-0353

Ju-Young Lee, https://orcid.org/0000-0003-2218-8625

Ae-Jung Im, https://orcid.org/0000-0003-2752-7112

Do-Seon Lim, https://orcid.org/0000-0003-4602-3323

\section{Acknowledgements}

This study was supported by research fund from Chosun University, 2019.

\section{References}

1. Bahal P, Djemal S: Dental erosion from an excess of vitamin C. Case Rep Dent 2014: 485387, 2014. https://doi.org/10.1155/2014/485387

2. Shin SC: Drinking, smoking, drug, food and oral health. Dankook University Press, Seoul, 2009.

3. Park KH, Chung JH, Ki MC, Eun JB: A survey on Korean consumer attitude toward green tea. J Korean Tea Soc 2: 129-146, 1996.

4. Retrieved September 11, 2012, from http://mbnmoney.mbn. 
co.kr/news/view/news_no=mm1000681943(2012).

5. Nielsen Korea: 2014 Carbonated water sales trends. Retrieved January 25, 2015, from http://www.nielsen.com/ kr/ko/pressroom/2014/press-release-20141007.html.nielsen( 2014, October 7).

6. Nielsen Korea: 2014. Retrieved December 7, 2017, from http://www.nielsen.com/kr/ko/press-room/2014/press-release -20140813.html\#nielsen(2014, August 13).

7. Kim SH, Han JH, Zhu QY, Keen CL: Use of vitamins, minerals, and other dietary supplements by $17-$ and 18-year-old students in Korea. J Med Food 6: 27-42, 2003. https://doi.org/10.1089/109662003765184723

8. Stahl H: Effervescent dosage manufacturing. Pharm Technol Eur 15: 25-28, 2003.

9. Featherstone JD, Mellberg JR: Relative rates of progress of artificial carious lesions in bovine, ovine and human enamel. Caries Res 15: 109-114, 1981. https://doi.org/10.1159/000260508

10. Schroeder PL, Filler SJ, Ramirez B, Lazarchik DA, Vaezi MF, Richter JE: Dental erosion and acid reflux disease. Ann Intern Med 122: 809-815, 1995. https://doi.org/10.7326/0003-4819-122-11-199506010-00001

11. Johansson AK, Johansson A, Birkhed D, et al.: Dental erosion associated with soft-drink consumption in young Saudi men. Acta Odontol Scand 55: 309-397, 1997. https://doi.org/10.3109/00016359709059205

12. Lussi A, Megert B, Shellis RP, Wang X: Analysis of the erosive effect of different dietary substances and medications. Br J Nutr 107: 252-262, 2012. https://doi.org/10.1017/S0007114511002820

13. Nunn JH, Ng SK, Sharkey I, Coulthard M: The dental implications of chronic use of acidic medicines in medically compromised children. Pharm World Sci 23: 118-119, 2001. https://doi.org/10.1023/a:1011202409386

14. Attin T, Weiss K, Becker K, Buchalla W, Wiegand A: Impact of modified acidic soft drinks on enamel erosion. Oral Dis 11: 7-12, 2005. https://doi.org/10.1111/j.1601-0825.2004.01056.x

15. Choi CH, Youn HJ, Noh HJ, Hong SJ: Surface microhardness changes caused by Coca-cola on sound enamel of bovine teeth. J Korean Acad Oral Health 32: 152-159, 2008.

16. Sim JH, Jeong TS, Kim S: A study on the enamel erosion by fremented milks. J Korean Acad Pediatr Dent 31: 555-563,
2004.

17. Brunton PA, Hussain A: The erosive effect of herbal tea on dental enamel. J Dent 29: 517-520, 2001. https://doi.org/10.1016/s0300-5712(01)00044-6

18. Birkhed D: Sugar content, acidity and effect on plaque $\mathrm{pH}$ of fruit juices, fruit drinks, carbonated beverages and sport drinks. Caries Res 18: 120-127, 1984. https://doi.org/10.1159/000260759

19. Hooper S, West NX, Sharif N, et al.: A comparison of enamel erosion by a new sports drink compared to two proprietary products: a controlled, crossover study in situ. J Dent 32: 541-545, 2004. https://doi.org/10.1016/j.jdent.2004.05.002

20. Sánchez GA, Fernandez De Preliasco MV: Salivary $\mathrm{pH}$ changes during soft drinks consumption in children. Int $\mathrm{J}$ Paediatr Dent 13: 251-257, 2003. https://doi.org/10.1046/j.1365-263x.2003.00469.x

21. Wegehaupt FJ, Lunghi N, Hogger VM, Attin T: Erosive potential of vitamin and vitamin+mineral effervescent tablets. Swiss Dent J 126: 457-465, 2016.

22. Choi SH, Lee $\mathrm{CH}$, Ahn SH: Dentinal micro-hardness and enamel surface change in deciduous teeth by intake some candies containing vitamins. Int J Clin Prev Dent 8: 65-72, 2012.

23. Kim DE, Kim KH, Kim AO, et al.: Effect of red vinegar drink on the surface of sound enamel. J Korean Acad Oral Health 38: 184-190, 2014. https://doi.org/10.11149/jkaoh.2014.38.3.184

24. Lee ES: New marketing paradigm for the beverage industry in the 21C. Marketing 34: 36-39, 2000.

25. Choi DY, Shin SC: A study on $\mathrm{pH}$ of several beverages in Korea. J Korean Acad Oral Health 20: 399-410, 1996.

26. Meurman JH, Murtomaa H: Effect of effervescent vitamin C preparations on bovine teeth and on some clinical and salivary parameters in man. Scand J Dent Res 94: 494-499, 1986. https://doi.org/10.1111/j.1600-0722.1986.tb01791.x

27. Larsen MJ, Nyvad B: Enamel erosion by some soft drinks and orange juices relative to their $\mathrm{pH}$, buffering effect and contents of calcium phosphate. Caries Res 33: 81-87, 1999. https://doi.org/10.1159/000016499

28. Fuller JL, Johnson WW: Citric acid consumption and the human dentition. J Am Dent Assoc 95: 80-84, 1977. https://doi.org/10.14219/jada.archive.1977.0551

29. Rytömaa I, Meurman JH, Koskinen J, Laakso T, Gharazi L, 
Turunen R: In vitro erosion of bovine enamel caused by acidic drinks and other foodstuffs. Scand J Dent Res 96: 324-333, 1988.

https://doi.org/10.1111/j.1600-0722.1988.tb01563.x

30. Lussi A, Schaffner M: Progression of and risk factors for dental erosion and wedge-shaped defects over a 6-year period. Caries Res 34: 182-187, 2000.

https://doi.org/10.1159/000016587

31. O'Sullivan EA, Curzon ME: A comparison of acidic dietary factors in children with and without dental erosion. ASDC J Dent Child 67: 186-192, 160, 2000.

32. Lee CK, Kim JS, Yoo SH: Comparative study on the rate of dental enamel demineralization using quantitative lightinduced fluorescence. J Korean Acad Pediatr Dent 31: 506-515, 2004.

33. Lee CY, Kim S, Jung TS: A study on the enamel erosion caused by orange juices. J Korean Acad Pediatr Dent 31:
617-623, 2004.

34. Jenkins GN: Enamel protective factors in food. J Dent Res 49: 1318-1326, 1970.

https://doi.org/10.1177/00220345700490062501

35. White W, Nancollas GH: Quantitative study of enamel dissolution under conditions of controlled hydrodynamics. J Dent Res 56: 524-530, 1977. https://doi.org/10.1177/00220345770560051301

36. Kim JW: A study on the enamel erosion caused by acidic beverage and rehardening by intraoral exposure. J Korean Acad Pediatr Dent 25: 312-322, 1998.

37. Maupomé G, Aguilar-Avila M, Medrano-Ugalde H, BorgesYáñez A: In vitro quantitative microhardness assessment of enamel with early salivary pellicles after exposure to an eroding cola drink. Caries Res 33: 140-147, 1999. https://doi.org/10.1159/000016508 